\title{
Biometric relationships of ocular components in esotropic amblyopia
}

\section{Relações entre medidas ecobiométricas dos componentes oculares em ambliopia por esotropia}

\author{
Iara Debert ${ }^{1}$, Mariza Polati ${ }^{1}$, Daniela Lima de Jesus ${ }^{1}$, Eliane Cardoso dos Santos Souza², Milton Ruiz Alves ${ }^{1}$
}

\begin{abstract}
Purpose: To investigate the contribution of the individual ocular components, i.e. anterior chamber depth, lens thickness and vitreous chamber depth, to total axial length in patients with esotropic amblyopia.

Methods: The study population consisted of 74 children, aged between 5 and 8 years: thirty-seven patients with esotropic amblyopia and 37 healthy volunteers (control group). The participants underwent a comprehensive ophthalmological examination, including cycloplegic refraction and A-scan ultrasonography. Anterior chamber depth, lens thickness, vitreous chamber depth and total axial length were recorded. Paired Student's t-tests were used to compare biometric measurements between amblyopic eyes and their fellow eyes and between right and left eyes in the control group. To evaluate the contribution of the ocular components to the total axial length, we report the individual components as a percentage of total axial length.

Results: The comparison between amblyopic and fellow eyes regarding the individual contribution from ocular components to the total axial length revealed greater contribution from lens thickness $(P=0.001)$ and smaller contribution from vitreous chamber depth $(P=0.001)$ in amblyopic eyes, despite similar contribution from anterior chamber depth $(P=0.434)$. The comparison between right and left eyes in the control group showed similar contributions from anterior chamber depth $(P=0.620)$, lens thickness $(P=0.721)$, and vitreous chamber depth $(P=0.483)$.

Conclusions: This study shows differences between amblyopic and non-amblyopic eyes when the total axial length is broken down into the individual contribution from the ocular components.
\end{abstract}

Keywords: Amblyopia; Axial length, eye; Lens, crystalline; Esotropia; Ultrasonography

\section{RESUMO}

Objetivo: Investigar a contribuição individual da profundidade da câmara anterior, da espessura do cristalino e da profundidade da câmara vítrea para o comprimento axial total em pacientes com ambliopia por esotropia.

Métodos: Foram incluidas 74 crianças com idade entre 5 e 8 anos, sendo 37 pacientes com ambliopia por esotropia e 37 voluntários sadios (grupo controle). Foi realizado exame oftalmológico completo, incluindo refração sob cicloplegia e ultrassonografia modo A. Foram registrados profundidade da câmara anterior, espessura do cristalino, profundidade dacâmaravítrea e comprimento axial total. A contribuição individual de cada componente para o comprimento axial total foi relatada como valor porcentual e teste t de Student pareado foi utilizado para a comparação entre olho amblíope e olho contralateral e entre olho direito e esquerdo no grupo controle.

Resultados: Olhos amblíopes, quando comparados aos olhos contralaterais, apresentaram maior contribuição da espessura do cristalino $(P=0,001)$, menor contribuição da profundidade da câmara vítrea $(P=0,001)$ e contribuição semelhante da profundidade da câmara anterior $(P=0,434)$ para o comprimento axial total. A comparação entreolho direito e olho esquerdo no grupo controle mostrou contribuições semelhantes da profundidade da câmara anterior $(p=0,620)$, da espessura do cristalino $(P=0,721)$ e da profundidade da câmara vitrea $(P=0,483)$ para o comprimento axial total.

Conclusões: Este estudo mostrou diferenças entre olhos amblíopes e não amblíopes quando o comprimento axial total é dividido nas contribuições individuais dos seus componentes.

Descritores:Ambliopia; Comprimento axial do olho; Cristalino; Esotropia; Ultrassonografia

\section{INTRODUCTION}

Amblyopia is the most common cause of monocular visual impairment in children and young adults. It is a disorder in which there is processing of visual information dysfunction. This dysfunction is usually detected as reduced best-corrected visual acuity in one or both eyes, which cannot be attributed to the direct effect of any structural abnormality of the visual pathway ${ }^{(1,2)}$. Amblyopia is believed to be caused by abnormal visual experience early in life resulting from strabismus, anisometropia, bilateral high refractive errors or visual deprivation ${ }^{(3-5)}$. In special, esotropia is the most common cause of strabismic and combined (strabismic and anisometropic) amblyopia ${ }^{(6,7)}$.

Previous studies reported that esotropic amblyopic eyes are shorter than their fellow eyes ${ }^{(8,9)}$. Although most researchers agree that refractive error is in large part genetically determined, a growing body of evidence shows that visual experiences early in life may influence ocular growth and eventual refractive status ${ }^{(10)}$. One previous longitudinal study that followed strabismic amblyopes observed that in children with hyperopia, the axial length increased less in the amblyopic eye when compared to the fellow eye, suggesting that good vision influences the ocular growth rate ${ }^{(11)}$. These findings are in agreement with animal studies, which have shown that abnormal visual input alters postnatal eye growth. Monocular deprivation of form vision, for example, by lid-suture or occlusion, resulted in excessive ocular elongation ${ }^{(12-14)}$. In contrast, less severe deprivation, for example, caused by chronic unilateral atropinization, resulted in reduced axial elongation ${ }^{(15)}$.

The precise mechanisms coordinating the optical and structural development of the eye are poorly understood, but evidences suggest that there is a process of emmetropization, by which the hyperopic eye of a newborn is progressively directed towards emmetropia. There is a very fast eye growth during the first 3 years of age, the rate growth then slows, and axial length reaches its adult size around 15 years of age ${ }^{(16,17)}$. The relationships between the biometric parameters were studied in normal adult eyes and showed: positive correlations between lens thickness and age, spherical equivalent and age, axial length and anterior chamber depth; negative correlations between anterior chamber depth and age, vitreous chamber depth and age, spherical equivalent and years of formal education ${ }^{(18)}$. 
The emmetropization process involves the coordination of postnatal axial elongation with the maturation of one's refractive components ${ }^{(19,20)}$. Eyes with amblyopia represent a group in which there is an abnormal visual input and this could be associated with impaired modulation of axial growth. Most previous investigations on amblyopic eyes ${ }^{(8,9,11)}$ concentrated solely on the total axial length, not on the contribution of each ocular component to the total axial length. Only one study evaluated the contribution of anterior chamber depth, lens thickness and vitreous chamber depth as percentages of axial length in strabismic amblyopes. They found that the contribution of anterior chamber depth and vitreous chamber depth to axial length were similar between amblyopic and fellow eyes. However, lens thickness contributed more to the total axial length in the amblyopic eye when compared to the fellow eye ${ }^{(21)}$. Nevertheless, these investigators included only 18 strabismic patients and used through-the-lid A-scan ultrasound biometry. It is known that through-the-lid biometry is relatively inaccurate when compared to corneal contact method, due to the lack of control of patient fixation during the test ${ }^{(22)}$.

The purpose of our study was to investigate the contribution of each individual ocular component, i.e. anterior chamber depth, lens thickness and vitreous chamber depth, to total axial length in patients with esotropic amblyopia.

\section{METHODS}

The study population consisted of 74 children: thirty-seven consecutive patients with esotropic amblyopia selected from the Strabismus Service of the Department of Ophthalmology of the University of São Paulo and 37 healthy volunteers (control group). Ethical approval was obtained from the University of São Paulo Research Ethics Committee/Investigational Review Board (Project number 0315/08). Parents provided written informed consent and study subjects gave assent after all procedures were explained. The study protocol adhered to the tenets of the Declaration of Helsinki.

All subjects underwent a comprehensive ophthalmological examination, including visual acuity assessment, ocular motility examination, sensory binocular function evaluation, cycloplegic refraction, biomicroscopy, indirect ophthalmoscopy, and A-scan ultrasonography. All measurements were carried out by the same investigator and tests were performed at the same visit.

The inclusion criteria for all the participants were age between 5 and 8 years old and bilateral hyperopia, defined as refractive error of at least $+1.00 \mathrm{D}$ in all meridians. Exclusion criteria were astigmatism (in either eye) $>1.5 \mathrm{D}$ at $90^{\circ}$ or $180^{\circ},>1.0 \mathrm{D}$ in oblique axis $\left(>10^{\circ}\right.$ eccentric to $90^{\circ}$ or $180^{\circ}$ ), astigmatic anisometropia $\geq 1.0 \mathrm{D}$, nystagmus, previous extraocular muscle surgery or intraocular surgery, any structural ocular anomalies, birth weight $\leq 2500 \mathrm{~g}$ or developmental delay. The inclusion criteria for the amblyopic subjects were esotropia and amblyopia, defined as a 2-line or more difference in best-corrected visual acuity between the eyes without an underlying ocular or neurological cause. All patients were undergoing occlusion therapy for at least 6 months. The control group required children without amblyopia, strabismus or any other ocular disease.

Monocular visual acuity was measured using a Lea symbols logMAR distance chart. Subjects were tested using optimal spectacle correction and visual acuity was recorded as the last line on which at least three of the five symbols were identified correctly. Monocularity was ensured with an adhesive patch attached to the skin. Ocular deviations were determined by prism and alternate cover test at distance and near fixation, with spectacle correction. Sensory fusion was evaluated using Bagolini striated lenses and stereopsis with a Titmus Stereo Test. Cycloplegia was obtained with 2 drops of 1\%, cyclopentolate separated by 5 minutes. One drop of $0.5 \%$ proparacaine hydrochloride was used before the cyclopentolate to minimize discomfort. Streak retinoscopy was performed 35 minutes after the initial instillation. Refractive error is reported as the spherical equivalent.
Anterior chamber depth, lens thickness, vitreous chamber depth and total axial length were measured through the dilated pupil with A-scan ultrasonography (Alcon Ultrascan) using a contact $10-\mathrm{MHz}$ transducer with a handheld probe on a semi-automated measurement mode. The cornea was anesthetized with a drop of $0.5 \%$ proparacaine hydrochloride. An average of ten readings for each, with a standard deviation (SD) of $\leq 0.10 \mathrm{~mm}$ was used. The children were in supine position and were asked to look at the light in the center of the ultrasound probe, which was gently placed on the central cornea. Care was taken to ensure that the measurement was on-axis and without indentation. The readings were obtained when a satisfactory scan image was achieved. Ultrasound records with small corneal or retinal peaks were deleted. A good image was defined as one with well-defined echoes corresponding to the cornea, the anterior and posterior poles of the lens, and the posterior wall of the eye. The ultrasonography unit was calibrated at the beggining of each testing session.

Student's t test was used to compare age between amblyopic group and control group. Paired Student's t-tests were used to compare refractive error and biometric measurements between amblyopic eyes and their fellow eyes and between right and left eyes in the control group. To evaluate the contribution of the ocular components to the total axial length, we report the individual components as a percentage of total axial length and paired Student's t-tests were used to compare interocular differences. The alpha level (type I error) was set at 0.05. Bonferroni correction was used to adjust for multiple comparisons. Sample size was calculated based on an expected difference of $0.1 \mathrm{~mm}$ on axial length between amblyopic and fellow eyes. A pilot study on 10 patients revealed a $0.2 \mathrm{~mm}$ standard deviation for this difference. The necessary sample size for an expected 95\% confidence level and 80\% power was 31 cases and 31 controls.

\section{RESULTS}

Both groups were similar with respect to age: mean \pm SD was $6.8 \pm 1.3$ years in the amblyopic group and $7.3 \pm 1.1$ years in the control group $(P=0.059)$. Mean $\pm S D$ visual acuity in the amblyopic eye was $0.35 \pm 0.21 \mathrm{log} M A R$ and in the fellow eye was $0.06 \pm 0.09 \log M A R$. In the control group, mean \pm SD visual acuity was $0.01 \pm 0.09$ logMAR in the right eye and $0.02 \pm 0.08$ logMAR in the left eye. In the amblyopic group, mean \pm SD ocular deviation was $16.8 \pm 13.8$ prism diopters at distance and $24.1 \pm 14.4$ prism diopters at near.

Sensory testing revealed in all amblyopic patients suppression of the amblyopic eye on Bagolini striated lenses and no stereopsis (worse than 3000 arc-seconds) on the Titmus stereo test. In all the subjects from the control group, sensory testing showed simultaneous macular perception on Bagolini striated lenses and stereopsis better than or equal to 50 arc-seconds on the Titmus stereo test.

Table 1 shows the comparison of refractive error and ocular components between amblyopic and fellow eyes. We observed more hyperopia, shorter vitreous chamber depth and shorter axial length in amblyopic eyes, despite similar anterior chamber depth and lens thickness. Table 2 shows the comparison between amblyopic and fellow eyes for each individual ocular component's contribution to the total axial length. We observed greater contribution from lens thickness and smaller contribution from vitreous chamber depth in amblyopic eyes, despite similar contribution from anterior chamber depth.

Table 3 shows the comparison of refractive error and ocular components between right and left eyes in the control group. We observed no differences regarding refractive error or ocular components. Table 4 shows the comparison between right and left eyes in the control group for each individual ocular component's contribution to the total axial length and we observed similar contributions.

Figure 1 shows the interocular differences of ocular components expressed as a percentage of total axial length in amblyopic patients. 
Table 1. Comparison of refractive error and ocular components between amblyopic eyes and fellow eyes

\begin{tabular}{lccc}
\hline & $\begin{array}{c}\text { Amblyopic eyes } \\
\mathbf{( n = 3 7 )} \\
\mathbf{m e a n} \pm \mathbf{S D}\end{array}$ & $\begin{array}{c}\text { Fellow eyes } \\
\mathbf{( n = 3 7 )} \\
\text { mean } \pm \text { SD }\end{array}$ & $\begin{array}{c}\text { P value } \\
\text { (t-test) }\end{array}$ \\
\hline Spherical equivalent refractive error (D) & $3.71 \pm 1.71$ & $3.15 \pm 1.48$ & $<0.001$ \\
Anterior chamber depth (mm) & $3.38 \pm 0.17$ & $3.40 \pm 0.19$ & 0.194 \\
Lens thickness (mm) & $3.52 \pm 0.15$ & $3.51 \pm 0.14$ & 0.205 \\
Vitreous chamber depth (mm) & $14.71 \pm 0.90$ & $14.89 \pm 0.85$ & $<0.001$ \\
Axial length (mm) & $21.61 \pm 0.93$ & $21.80 \pm 0.88$ & $<0.001$ \\
\hline SD standard deviation; $\mathrm{D}=$ diopters & &
\end{tabular}

Table 2. Comparison between amblyopic and fellow eyes for each individual ocular component's contribution to the total axial length

\begin{tabular}{lccc}
\hline & $\begin{array}{c}\text { Amblyopic eyes } \\
(\mathbf{n}=\mathbf{3 7}) \\
\text { mean } \pm \text { SD }\end{array}$ & $\begin{array}{c}\text { Fellow eyes } \\
(\mathbf{n = 3 7 )} \\
\text { mean } \pm \text { SD }\end{array}$ & $\begin{array}{c}\text { P value } \\
\text { (t-test) }\end{array}$ \\
\hline Anterior chamber depth (\%) & $15.65 \pm 0.73$ & $15.60 \pm 0.83$ & 0.434 \\
Lens thickness (\%) & $16.34 \pm 1.07$ & $16.13 \pm 0.96$ & 0.001 \\
Vitreous chamber depth (\%) & $68.01 \pm 1.48$ & $68.28 \pm 1.42$ & 0.001 \\
\hline
\end{tabular}

$\mathrm{SD}=$ standard deviation

Table 3. Comparison of refractive error and ocular components between right and left eyes in the control group

\begin{tabular}{|c|c|c|c|}
\hline & $\begin{array}{l}\text { Right eyes } \\
\quad(n=37) \\
\text { mean } \pm \text { SD }\end{array}$ & $\begin{array}{l}\text { Left eyes } \\
(n=37) \\
\text { mean } \pm \text { SD }\end{array}$ & $\begin{array}{l}\text { P value } \\
\text { (t-test) }\end{array}$ \\
\hline Spherical equivalent refractive error (D) & $1.60 \pm 0.87$ & $1.58 \pm 0.88$ & 0.606 \\
\hline Anterior chamber depth (mm) & $3.52 \pm 0.24$ & $3.53 \pm 0.24$ & 0.602 \\
\hline Lens thickness (mm) & $3.50 \pm 0.13$ & $3.51 \pm 0.12$ & 0.598 \\
\hline Vitreous chamber depth (mm) & $15.41 \pm 0.84$ & $15.40 \pm 0.81$ & 0.772 \\
\hline Axial length (mm) & $22.43 \pm 0.88$ & $22.44 \pm 0.84$ & 0.917 \\
\hline
\end{tabular}

$\mathrm{SD}=$ standard deviation; $\mathrm{D}=$ diopters

Table 4. Comparison between right and left eyes in the control group for each individual ocular component's contribution to the total axial length

\begin{tabular}{lccc}
\hline & $\begin{array}{c}\text { Right eyes } \\
(\mathbf{n}=\mathbf{3 7 )} \\
\text { mean } \pm \text { SD }\end{array}$ & $\begin{array}{c}\text { Left eyes } \\
\text { (n=37) } \\
\text { mean } \pm \text { SD }\end{array}$ & $\begin{array}{c}\text { P value } \\
\text { (t-test) }\end{array}$ \\
\hline Anterior chamber depth (\%) & $15.69 \pm 1.05$ & $15.72 \pm 1.07$ & 0.620 \\
Lens thickness (\%) & $15.63 \pm 0.91$ & $15.65 \pm 0.86$ & 0.721 \\
Vitreous chamber depth (\%) & $68.67 \pm 1.35$ & $68.63 \pm 1.33$ & 0.483 \\
\hline
\end{tabular}

$\mathrm{SD}=$ standard deviation

\section{DISCUSSION}

Our study shows a disproportionately greater contribution from lens thickness in amblyopic eyes compared to fellow eyes when the total axial length is broken down into the individual contribution from the ocular components. One previous study found similar results and hypothesized that amblyopia may cause a stalling in the emmetropization process, leaving the lens disproportionately thicker ${ }^{(21)}$.

The role played by the ocular components in emmetropization in normal eyes is not completely understood. Most commonly, there is an associated reduction in corneal and lens refractive power as the eye grows, resulting in progressive reduction of hyperopia ${ }^{(23,24)}$. During emmetropization, both the anterior chamber and the vitreous chamber deepen, the cornea flattens and the lens flattens and become thinner due to equatorial stretch during the ocular sagittal expansion ${ }^{(25,26)}$. Some investigators have suggested that in amblyopia the lens is disproportionately thicker because the eye appears to be under-developed, as a result of impaired emmetropization in the infantile phase, before the lens thinning due to sagittal expansion of the globe ${ }^{(21)}$. Theories explaining the emmetropization process involve feedback mechanisms in which retinal image quality may affect axial 


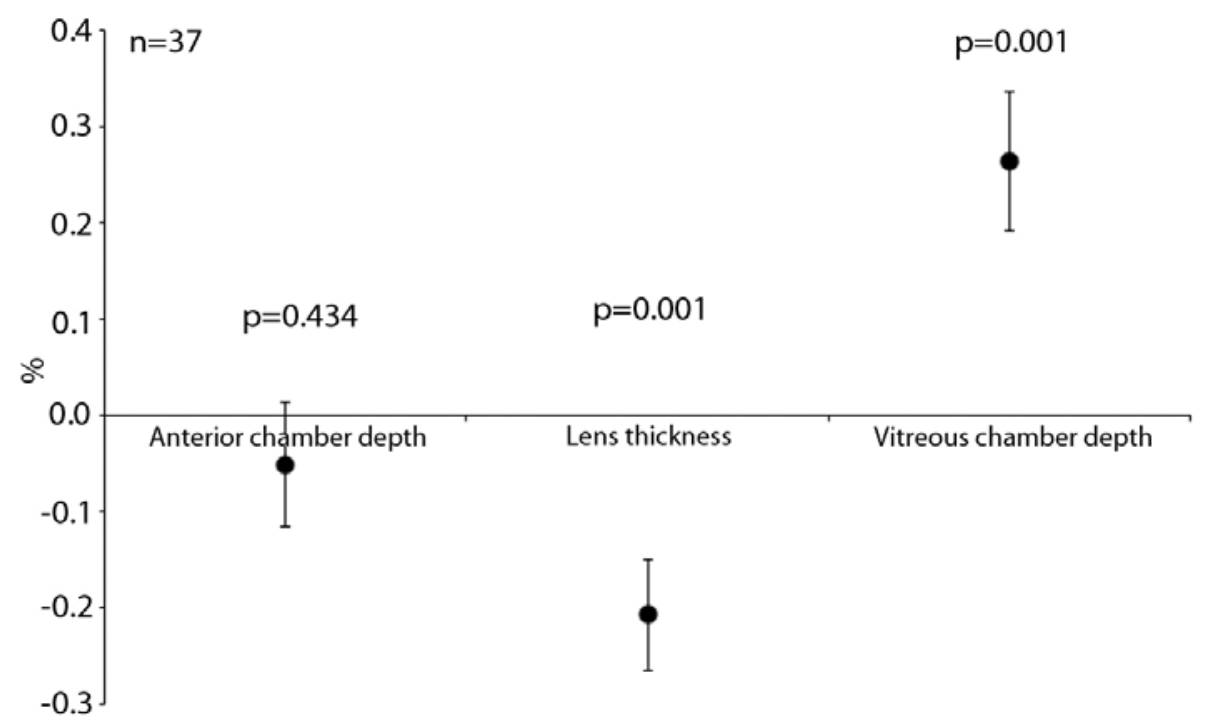

Figure 1. Interocular differences for the contribution of individual ocular components to the total axial length in amblyopic patients. The difference was calculated as the percentage contribution in the fellow eyes minus that of the amblyopic eyes. We observed no significant differences for anterior chamber depth, greater contribution from the lens thickness and smaller contribution from the vitreous chamber depth in amblyopic eyes.

elongation ${ }^{(20,27,28)}$. Amblyopic eyes, which have an abnormal visual input, may fail to achieve the needed balance between its ocular structures during emmetropization. In our study, vitreous chamber depth represented a smaller proportion of the total axial length in amblyopic eyes than it did in the fellow eyes. The axial elongation in normal eyes stabilizes around teenage years ${ }^{(16)}$, and therefore the ocular components observed in this study may still change over time, although it is not known if there is a different growth trend in amblyopic eyes. We found similar individual contribution from anterior chamber depth to total axial length in amblyopic and non-amblyopic eyes. This finding is consistent with the previous cited study(21).

Even though interocular differences for the individual contribution from lens thickness and vitreous chamber depth to total axial length in amblyopic patients were not clinically significant in our study, these represented statistically significant differences. The results from the control group indicated that there are no statistically significant interocular differences with respect to refractive error and ocular components in non-amblyopic hyperopic children.

We observed more hyperopia in the amblyopic eyes when compared to their fellow eyes. Even though there is no clear causal relationship, it is well known the association between hyperopic anisometropia and esotropic amblyopia ${ }^{(29-32)}$. Hyperopic anisometropia may be considered the cause of amblyopia, since hyperopic anisometropia can lead to the development of esotropia due to poor foveal fusion, and esotropia may cause amblyopia due to suppression of the affected eye. However, hyperopic anisometropia may be considered also the consequence of amblyopia, according to studies, both in animals ${ }^{(33)}$ and humans ${ }^{(34)}$, which have shown that amblyopia may be detected before the onset of anisometropia. One previous study with strabismic children showed a delay of some years between the diagnosis of strabismic amblyopia and the development of a refractive difference between the eyes ${ }^{(34)}$.

Limitations of the present study deserve consideration. We studied the developing eyes of children between 5 and 8 years old. It would be interesting to evaluate the contribution of the ocular components to the total axial length in younger children, as these parameters may change over time. We chose this age because we expected this to be the youngest age for which corneal contact A-scan biometric examination could be performed in an office setting without sedation. Another limitation is the fact that all participants were undergoing occlusion therapy at the time of the study. It is not known whether occlusion therapy, and associated improved visual acuity, could modify the eye growth rate. Because they still presented with amblyopia at the time of the study, we expected little effect on the results.

In this study, we observed statistically significant differences between amblyopic and non-amblyopic eyes regarding the individual contribution from ocular components to the total axial length. Because the existing literature is still extremely limited, further research is clearly needed to determine the significance of these findings. The hypothesis of a different growth trend in amblyopic eyes is an issue that calls for a longitudinal study following amblyopes over several years.

\section{REFERENCES}

1. Von Noorden GK. Factors involved in the production of amblyopia. Br J Ophthalmol. 1974:58(3):158-64.

2. Holmes JM, Clarke MP. Amblyopia. Lancet. 2006;367(9519):1343-51. Review.

3. Daw NW. Critical periods and amblyopia. Arch Ophthalmol. 1998;116(4):502-5.

4. Pineles SL, Demer JL. Bilateral abnormalities of optic nerve size and eye shape in unilateral amblyopia. Am J Ophthalmol. 2009;148(4):551-7. e2

5. Chua B, Mitchell P. Consequences of amblyopia on education, occupation, and long term vision loss. Br J Ophthalmol. 2004;88(9):1119-21. Comment in Br J Ophthalmol. 2004;88(9):1105-6.

6. Attebo K, Mitchell P, Cumming R, Smith W, Jolly N, Sparkes R. Prevalence and causes of amblyopia in an adult population. Ophthalmology. 1998;105(1):154-9.

7. Preslan MW, Novak A. Baltimore Vision Screening Project. Ophthalmology. 1996;103(1): 105-9.

8. Lempert P. Axial length-disc area ratio in esotropic amblyopia. Arch Ophthalmol. 2003; 121(6):821-4. Comment in Arch Ophthalmol. 2004;122(11):1732; author reply 1732-3.

9. Debert I, de Alencar LM, Polati M, Souza MB, Alves MR. Oculometric parameters of hyperopia in children with esotropic amblyopia. Ophthalmic Physiol Opt. 2011;31(4): 389-97.

10. Fredrick DR. Myopia: was mother right about reading in the dark? Br J Ophthalmol. 2001:85(5):509-10. Comment on Br J Ophthalmol. 2001:85(5):527-8.

11. Burtolo C, Ciurlo C, Polizzi A, Lantier PB, Calabria G. Echobiometric study of ocular growth in patients with amblyopia. J Pediatr Ophthalmol Strabismus. 2002;39(4):209-14.

12. Smith EL $3^{\text {rd }}$, Harwerth RS, Crawford ML, von Noorden GK. Observations on the effects of form deprivation on the refractive status of the monkey. Invest Ophthalmol Vis Sci. 1987;28(8):1236-45 
13. Troilo D, Judge SJ. Ocular development and visual deprivation myopia in the common marmoset (Callithrix jacchus). Vision Res. 1993;33(10):1311-24.

14. Tigges M, Tigges J, Fernandes A, Eggers HM, Gammon JA. Postnatal axial eye elongation in normal and visually deprived rhesus monkeys. Invest Ophthalmol Vis Sci. 1990; 31(6):1035-46.

15. Kiorpes L, Boothe RG, Hendrickson AE, Movshon JA, Eggers HM, Gizzi MS. Effects of early unilateral blur on the macaque's visual system. I. Behavioral observations. J Neurosci. 1987;7(5):1318-26.

16. Fredrick DR. Myopia. BMJ. 2002;324(7347):1195-9. Review.

17. Sorsby A, Leary GA. A longitudinal study of refraction and its components during growth. Spec Rep Ser Med Res Counc (G B). 1969;309:1-41.

18. Pereira GC, Allemann N. Biometria ocular, erro refrativo e sua relação com a estatura, idade, sexo e escolaridade em adultos brasileiros. Arq Bras Oftalmol. 2007;70(3):487-93.

19. Brown NP, Koretz JF, Bron AJ. The development and maintenance of emmetropia. Eye (Lond). 1999:13(Pt 1):83-92.

20. Rabin J, Van Sluyters RC, Malach R. Emmetropization: a vision-dependent phenomenon. Invest Ophthalmol Vis Sci. 1981;20(4):561-4.

21. Cass $K$, Tromans C. A biometric investigation of ocular components in amblyopia. Ophthalmic Physiol Opt. 2008;28(5):429-40.

22. Twelker JD, Kirschbaum S, Zadnik K, Mutti DO. Comparison of corneal versus throughthe-lid A-scan ultrasound biometry. Optom Vis Sci. 1997;74(10):852-8.

23. Sorsby A, Benjamin B, Bennett AG. Steiger on refraction: a reappraisal. Br J Ophthalmol. 1981;65(12):805-11

24. Troilo D. Neonatal eye growth and emmetropisation - a literature review. Eye (Lond). 1992;6(Pt 2):154-60.
25. Mutti DO, Mitchell GL, Jones LA, Friedman NE, Frane SL, Lin WK, et al. Axial growth and changes in lenticular and corneal power during emmetropization in infants. Invest Ophthalmol Vis Sci. 2005;46(9):3074-80.

26. Mutti DO, Zadnik K, Fusaro RE, Friedman NE, Sholtz RI, Adams AJ. Optical and structural development of the crystalline lens in childhood. Invest Ophthalmol Vis Sci. 1998; 39(1):120-33.

27. Goss DA, Wickham MG. Retinal-image mediated ocular growth as a mechanism for juvenile onset myopia and for emmetropization. A literature review. Doc Ophthalmol. 1995;90(4):341-75.

28. Tayah D, Coral-Ghanem V, Alves MR. Componentes oculares em anisometropia. Arq Bras Oftalmol. 2007;70(3):459-64

29. Abrahamsson M, Fabian G, Sjöstrand J. Refraction changes in children developing convergent or divergent strabismus. Br J Ophthalmol. 1992;76(12):723-7.

30. Robaei D, Rose KA, Kifley A, Cosstick M, Ip JM, Mitchell P. Factors associated with childhood strabismus: findings from a population-based study. Ophthalmology. 2006; 113(7):1146-53.

31. Weakley DR Jr, Birch E. The role of anisometropia in the development of accommodative esotropia. Trans Am Ophthalmol Soc. 2000;98:71-6; sdiscussion 76-9.

32. Almeder LM, Peck LB, Howland HC. Prevalence of anisometropia in volunteer laboratory and school screening populations. Invest Ophthalmol Vis Sci. 1990:31(11): 2448-55.

33. Kiorpes L, Wallman J. Does experimentally-induced amblyopia cause hyperopia in monkeys? Vision Res. 1995;35(9):1289-97.

34. Lepard CW. Comparative changes in the error of refraction between fixing and amblyopic eyes during growth and development. Am J Ophthalmol. 1975;80(3 Pt 2):485-90. 